\title{
Efeito do revenido na resistência à corrosão dos aços inoxidáveis supermartensíticos
}

\author{
Effect of tempering on the corrosion resistance of supermartensitic \\ stainless steels
}

\section{Ana Paula Ciscato Camillo \\ Aluna de Iniciação Científica, \\ Departamento de Engenharia de Materiais da Universidade Federal de São Carlos - DEMa/UFSCar E-mail: anapaulaciscato@yahoo.com.br}

\section{Carlos Alberto Della Rovere \\ Doutorando, Programa de Pós- Graduação em Ciência e Engenharia de Materiais da Universidade Federal de São Carlos - PPGCEM/UFSCar E-mail: carlosdrovere@hotmail.com}

\section{José Mario de Aquino \\ Doutorando, Programa de Pós- Graduação em Química da Universidade Federal de São Carlos - PPGQ/UFSCar \\ E-mail: zeaquino@yahoo.com.br}

\author{
Sebastião Elias Kuri \\ Professor Adjunto, Departamento \\ de Engenharia de Materiais da \\ Universidade Federal de São Carlos - \\ DEMa/UFSCar \\ E-mail:dsek@power.ufscar.br
}

\begin{abstract}
Resumo
Os aços inoxidáveis supermartensíticos são utilizados nas indústrias de petróleo e gás, pois aliam boas propriedades mecânicas, soldabilidade e excelente resistência à corrosão. Eles são endurecidos pelo tratamento térmico de têmpera e, para otimizar suas propriedades mecânicas, são submetidos ao revenimento. Durante o revenimento, ocorre precipitação de fases, que, dependendo dos parâmetros temperatura e tempo, induz alterações indesejadas nas propriedades desses aços. Nesse trabalho, o objetivo foi estudar a microestrutura e a resistência à corrosão de um aço inoxidável supermartensítico em diferentes condições de revenido $\left(550^{\circ} \mathrm{C}\right.$, $600^{\circ} \mathrm{C}$ e $650^{\circ} \mathrm{C}$ ). Observou-se, na microestrutura da amostra revenida a $650^{\circ} \mathrm{C}$, a formação de austenita e precipitados de cromo do tipo $\mathrm{Cr}_{3} \mathrm{C}_{2}$ e $\mathrm{Cr}_{7} \mathrm{C}_{3}$. As curvas de polarização indicaram que o tratamento térmico influencia o comportamento anódico, modificando a região passiva e as características do filme passivo. O revenido altera a resistência à corrosão, com o grau de sensitização diminuindo com o aumento de temperatura de $550^{\circ} \mathrm{C}$ para $650^{\circ} \mathrm{C}$, devido à recuperação das zonas empobrecidas de cromo.
\end{abstract}

Palavras-chave: Aço inoxidável supermartensítico, microestrutura, sensitização, técnicas eletroquímicas.

\begin{abstract}
Supermartensitic stainless steels have been used in the oil and gas industry for onshore and offshore tubing applications, due to their good mechanical properties, weldability and excellent corrosion resistance. They are hardened by quenching heat treatment, and to improve their toughness, are submitted to tempering. During the tempering, some phase precipitation occurs, which depending on the time and temperature parameters, produces some undesired changes in the steel properties. The aim of this research was to study the microstructure and the corrosion resistance of supermartensitic stainless steel in quenched and different tempered conditions $\left(550^{\circ} \mathrm{C}, 600^{\circ} \mathrm{C}\right.$ and $\left.650^{\circ} \mathrm{C}\right)$. At the microstructure of the $650^{\circ} \mathrm{C}$ tempered sample was observed the formation of austenite and precipitates of chromium, like $\mathrm{Cr}_{3} \mathrm{C}_{2}$ and $\mathrm{Cr}_{7} \mathrm{C}_{3}$. The polarization curves indicated that the heat treatment influences the anodic behavior, changing the passive region and the passive film characteristics. The tempering changes the corrosion resistance, decreasing the degree of sensitization when increasing the temperature from $550^{\circ} \mathrm{C}$ to $650^{\circ} \mathrm{C}$, this occurs due to the recovery of the chromium impoverished zones.
\end{abstract}

Keywords: Supermartensitic stainless steel, microstructure, sensitization, electrochemical tests. 


\section{Introdução}

Os aços inoxidáveis supermartensíticos são utilizados na indústria de petróleo e gás como uma alternativa prática e econômica para substituição dos aços carbono com inibidores de corrosão e parte dos inoxidáveis dúplex na construção de tubulações onshore e offshore (Smith \& Celant, 2002.). Eles são uma subclasse dos aços inoxidáveis martensíticos convencionais, que combinam baixos custos de produção e manutenção com melhor soldabilidade, propriedades mecânicas e resistência à corrosão. A melhoria no desempenho desses materiais foi o resultado obtido ao se manter baixo o teor de carbono (teor em torno de $0,01 \%$ ), aumentar o teor de níquel na faixa de 4 a $6 \%$ e adicionar os elementos de liga molibdênio e titânio (Kondo et al., 1999; Dufrane, 1999)

Os aços inoxidáveis supermartensíticos são endurecidos pelo tratamento térmico de têmpera e, para otimizar suas propriedades mecânicas, são submetidos ao revenimento. Contudo, como a martensita é uma fase metaestável, se houver suficiente ativação térmica, haverá a tendência de sua decomposição nos seus produtos mais estáveis, que são as fases ferrita e carbonetos do tipo $\mathrm{M}_{7} \mathrm{C}_{3} \mathrm{e}$ $\mathrm{M}_{23} \mathrm{C}_{6}$ (Crowe \& Pickering, 1960) e que, dependendo dos parâmetros temperatura e tempo de revenimento, podem induzir alterações indesejáveis nas propriedades desses aços (Truman, 1976; Lim et al., 1993; Miao et al.,1993).

O objetivo do presente trabalho foi estudar a microestrutura e a resistência à corrosão de um aço inoxidável supermartensítico em diferentes condições de revenido $\left(550^{\circ} \mathrm{C}, 600^{\circ} \mathrm{C}\right.$ e $\left.650^{\circ} \mathrm{C}\right)$ e como temperado. O estudo foi realizado através de microscopia ótica (MO), análise de difração de raios $\mathrm{X}$ (DRX), técnica de polarização anódica e técnica eletroquímica de reativação potenciocinética na versão de ciclo duplo (DL-EPR).

\section{Material e métodos}

O material estudado foi um aço inoxidável supermartensítico alta liga. A Tabela 1 apresenta a análise química do material.

Foram extraídos corpos-de-prova cilíndricos com $8 \mathrm{~mm}$ de altura e 1,13 cm de diâmetro. Esses corpos-de-prova foram submetidos à austenitização a $1050^{\circ} \mathrm{C}$ por 1 hora e temperados em água. As temperaturas de revenimento utilizadas foram de $550^{\circ} \mathrm{C}, 600^{\circ} \mathrm{C}$ e $650^{\circ} \mathrm{C}$, por 1 hora. Tais corpos-de-prova foram resfriados ao ar.

A caracterização microestrutural dos corpos-de-prova foi feita por meio de ataque metalográfico convencional com reagente de Villela (5 $\mathrm{ml}$ de $\mathrm{HCl}$ $+100 \mathrm{ml}$ de $\mathrm{C}_{2} \mathrm{H}_{5} \mathrm{OH}+1 \mathrm{~g}$ de ácido pícrico). A seguir, fez-se observação em microscópio ótico. As análises de difração de raios $\mathrm{X}$ foram feitas para identificar as fases presentes na microestrutura, seguindo as recomendações da norma ASTM E 975 - 95 (ASTM, 1998), operando com radiação $\mathrm{K} \alpha \mathrm{Cu}$ a $50 \mathrm{kV}$ e $100 \mathrm{~mA}$, com ângulo de varredura (20) de $5^{\circ}$ a $120^{\circ}$ e velocidade de varredura de $2 \%$ min.

Na realização dos ensaios eletroquímicos, foi utilizada uma cela eletroquímica convencional de três eletrodos, com eletrodo auxiliar de platina e eletrodo de referência de calomelano saturado (ECS). Os eletrodos de trabalho foram construídos com os corpos-de-prova citados anteriormente. Os ensaios eletroquímicos foram realizados em soluções naturalmente aeradas e em temperaturas próximas de $25^{\circ} \mathrm{C}$. Foram feitas três medidas para cada eletrodo de trabalho e todas as medidas foram programadas para se iniciarem após 1 hora de estabilização no potencial de circuito aberto, se não fosse registrado uma variação de $1 \mathrm{mV}$ em 180s. Esse potencial de início das medidas foi definido como potencial de corrosão, $\mathrm{E}_{\text {corr }}$.

As curvas de polarização anódica potenciodinâmica foram feitas em soluções de ácido sulfúrico $\left(\mathrm{H}_{2} \mathrm{SO}_{4}\right)$ 0,05 M, com varredura de potenciais, no sentido anódico, com velocidades de varredura de $1 \mathrm{mV} / \mathrm{s}$, partindo-se de um potencial $100 \mathrm{mV}$ abaixo do potencial de corrosão até $1600 \mathrm{mV}$.
$\mathrm{O}$ ensaio de DL-EPR foi feito em solução de $\mathrm{H}_{2} \mathrm{SO}_{4} 0,5 \mathrm{M}+\mathrm{KSCN}$ 0,01M, com varredura de potenciais, no sentido anódico, com velocidade de varredura de $1,67 \mathrm{mV} / \mathrm{s}$, partindo-se de um potencial $100 \mathrm{mV}$ abaixo do potencial de corrosão. Em $500 \mathrm{mV}$, reverteu-se a varredura de potenciais para o sentido catódico, terminando a varredura em - $500 \mathrm{mV}$. Através desse ensaio, foram obtidos valores máximos de densidade de corrente na etapa de ativação $\left(I_{a}\right)$ e na de reativação $\left(\mathrm{I}_{\mathrm{r}}\right)$. $\mathrm{O}$ grau de sensitização foi medido através do quociente entre os dois máximos de densidade de corrente $\left(\mathrm{I}_{\mathrm{r}} / \mathrm{I}_{\mathrm{a}}\right)$. As microestruturas resultantes, após o ensaio, foram observadas em microscópio eletrônico de varredura.

\section{Resultados}

As Figuras 1 e 2 apresentam, respectivamente, as microestruturas características e os difratogramas do aço inoxidável supermartensítico para os diferentes tratamentos térmicos.

Tabela 1 - Composição química do metal.

\begin{tabular}{c|c}
\hline Elemento & $(\%)$ \\
\hline $\mathrm{C}$ & 0,01 \\
\hline $\mathrm{Si}$ & 0,17 \\
\hline $\mathrm{Mn}$ & 0,47 \\
\hline $\mathrm{P}$ & 0,012 \\
\hline $\mathrm{S}$ & 0,001 \\
\hline $\mathrm{Cr}$ & 12,01 \\
\hline $\mathrm{Ni}$ & 6,4 \\
\hline $\mathrm{Mo}$ & 2,42 \\
\hline $\mathrm{Ti}$ & 0,1 \\
\hline $\mathrm{V}$ & 0,05 \\
\hline $\mathrm{Cu}$ & 0,02 \\
\hline $\mathrm{O}$ & 0,011 \\
\hline $\mathrm{N}$ & 0,0055 \\
\hline
\end{tabular}




\begin{abstract}
A Figura 2 mostra que só ocorreu formação de austenita na amostra revenida a $650^{\circ} \mathrm{C}$. Além disso, é possível observar a formação de precipitados do tipo $\mathrm{M}_{7} \mathrm{C}_{3}$ nas amostras revenidas a 600 e $650^{\circ} \mathrm{C}$.
\end{abstract}

A Figura 3 apresenta as curvas de polarização para os diferentes tratamentos térmicos. Observa-se que o comportamento anódico depende do tratamento térmico, uma vez que as curvas apresentam diferentes valores de densidade de corrente na região ativa e no patamar passivo.

A Figura 4 apresenta as curvas de polarização do ensaio de reativação potenciodinâmica para os diferentes tratamentos térmicos. A partir dessas curvas, foram obtidos valores médios dos quocientes entre os dois máximos de densidade de corrente $\left(\mathrm{I}_{\mathrm{r}} / \mathrm{I}_{\mathrm{a}}\right)$, os quais são apresentados na Figura 5.

A Figura 5 mostra que o tratamento térmico de revenimento afeta a resistência à corrosão dos aços supermartensíticos, com o grau de sensitização diminuindo com o aumento de temperatura de $550^{\circ} \mathrm{C}$ para $650^{\circ} \mathrm{C}$.

A Figura 6 apresenta as imagens de MEV da superfície das amostras após o ensaio DL-EPR.
As imagens de MEV indicam que a amostra revenida a $550^{\circ} \mathrm{C}$ possui o aspecto de uma corrosão generalizada com maior intensidade, embora com padrão diferente da amostra temperada.

\section{Discussões}

A matriz da amostra temperada é composta, basicamente, de blocos de martensita temperada. Nas amostras revenidas, a microestrutura é classificada, segundo a literatura, como sendo composta, basicamente, de blocos de martensita revenida, carbonetos precipitados entre as ripas e austenita retida (Dufrane, 1999).
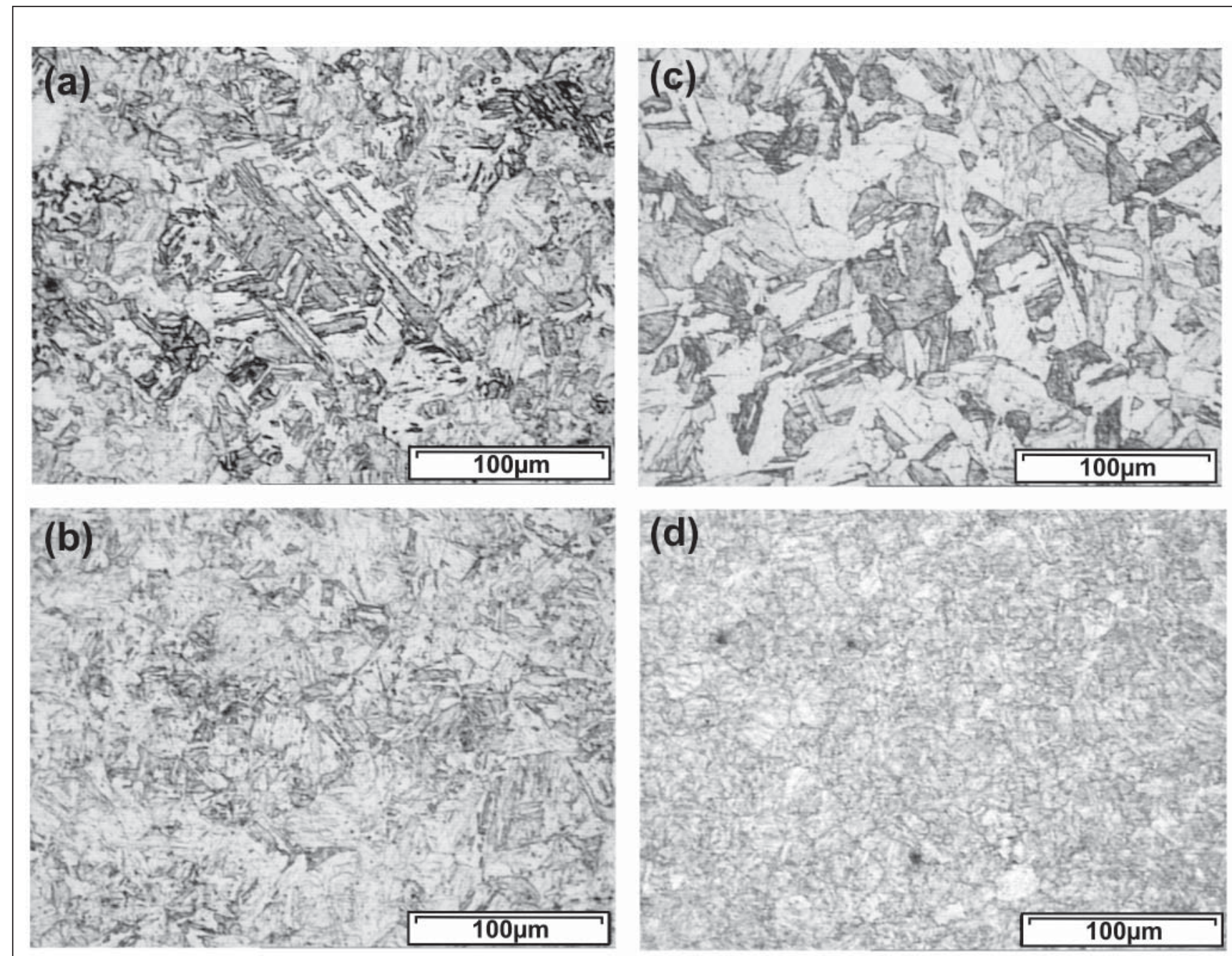

Figura 1 - Microestruturas do aço inoxidável supermartensítico (a) temperado, (b) revenido a $550^{\circ} \mathrm{C}$, (c) revenido a $600^{\circ} \mathrm{Ce}$ (d) revenido a $650^{\circ} \mathrm{C}$. 


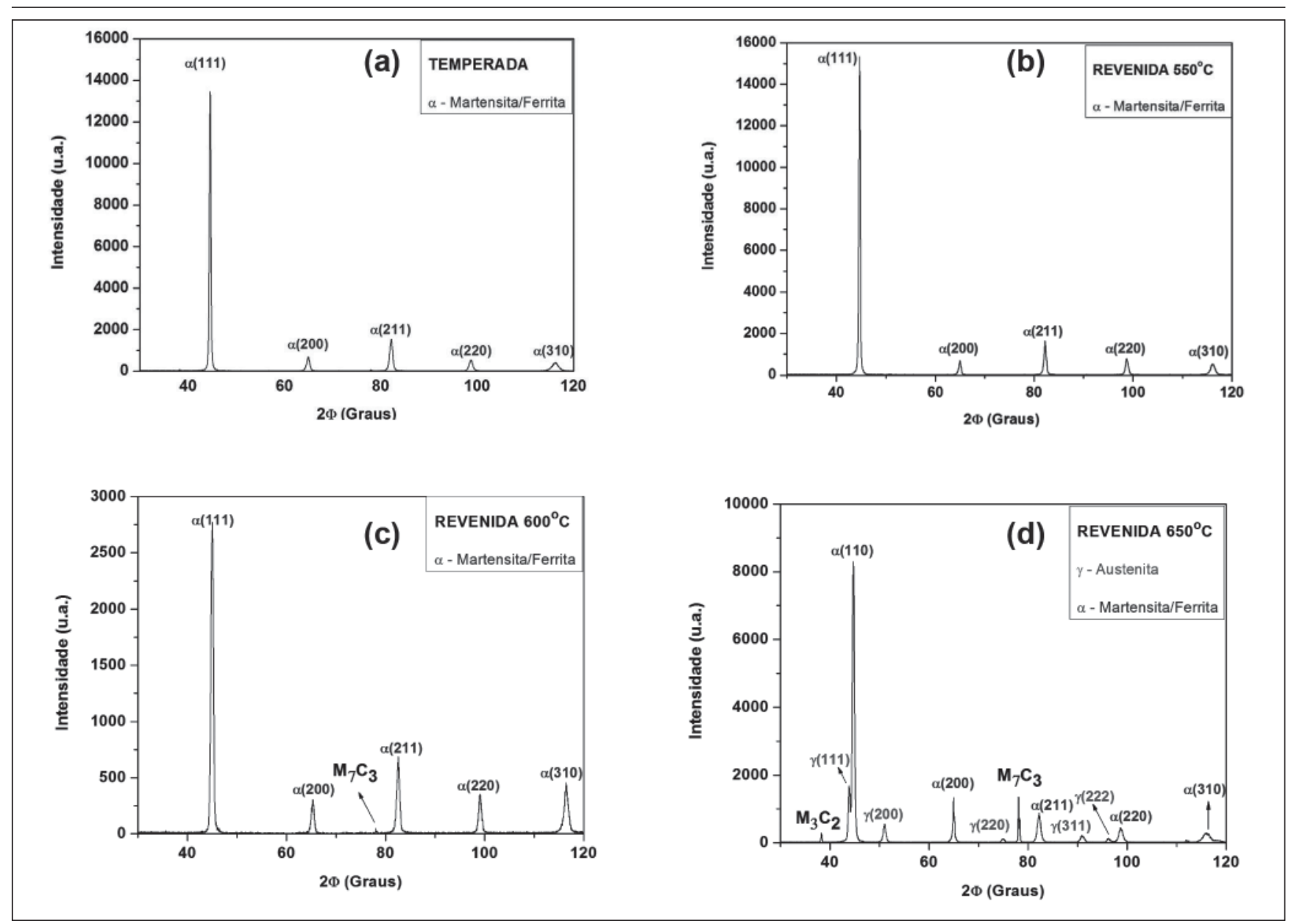

Figura 2 - Difratogramas de raios $\mathrm{X}$ do aço inoxidável supermartensítico (a) temperado, (b) revenido a $550^{\circ} \mathrm{C}$, (c) revenido a $600^{\circ} \mathrm{C}$ e (d) revenido a $650^{\circ} \mathrm{C}$.

Nas Figuras 2 (a) e (b), observa-se que os difratogramas das amostras temperada e revenida a $550^{\circ} \mathrm{C}$ apresentam um padrão semelhante com a presença marcante de picos característicos da martensita. Entretanto pode-se supor que, na temperatura de $550^{\circ} \mathrm{C}$, já ocorra alguma precipitação de fases, em pequenas quantidades volumétricas imperceptíveis à técnica de difração de raios X.

O difratograma da amostra revenida a $600^{\circ} \mathrm{C}$ apresentado na Figura 2 (c) indica um inicio da precipitação de carboneto de cromo do tipo $\mathrm{Cr}_{7} \mathrm{C}_{3}$, fato observado pela formação de pico característico O difratograma da amostra revenida a $650^{\circ} \mathrm{C}$ indica a formação de austenita e precipitados de cromo do tipo $\mathrm{Cr}_{3} \mathrm{C}_{2}$ e $\mathrm{Cr}_{7} \mathrm{C}_{3}$. A presença de austenita, nessa amostra, ocorre, pois a temperatura de $650^{\circ} \mathrm{C}$ está muito próxima da temperatura de início da formação da austenita $\left(\mathrm{Ac}_{1}\right)$. Essa austenita está

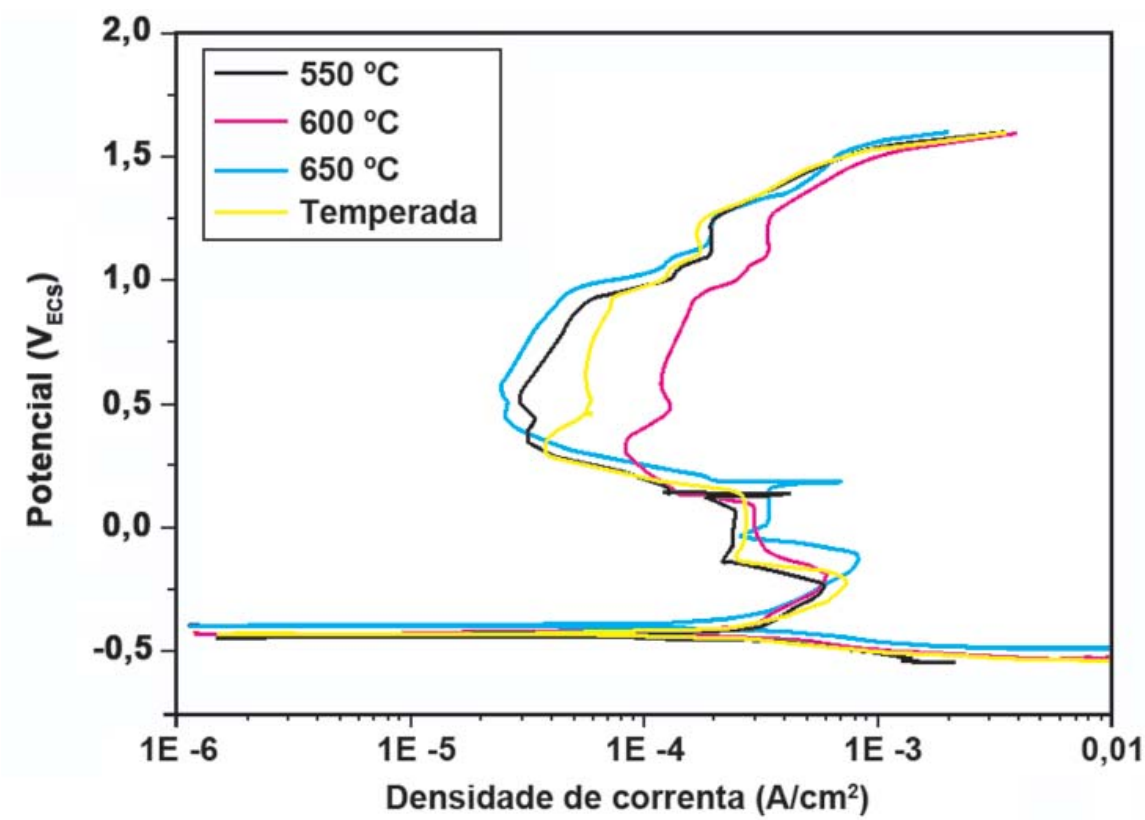

Figura 3 - Curvas de polarização potenciodinâmicas em $\mathrm{H}_{2} \mathrm{SO}_{4} 0,1 \mathrm{M}$ para os diferentes tratamentos térmicos. 

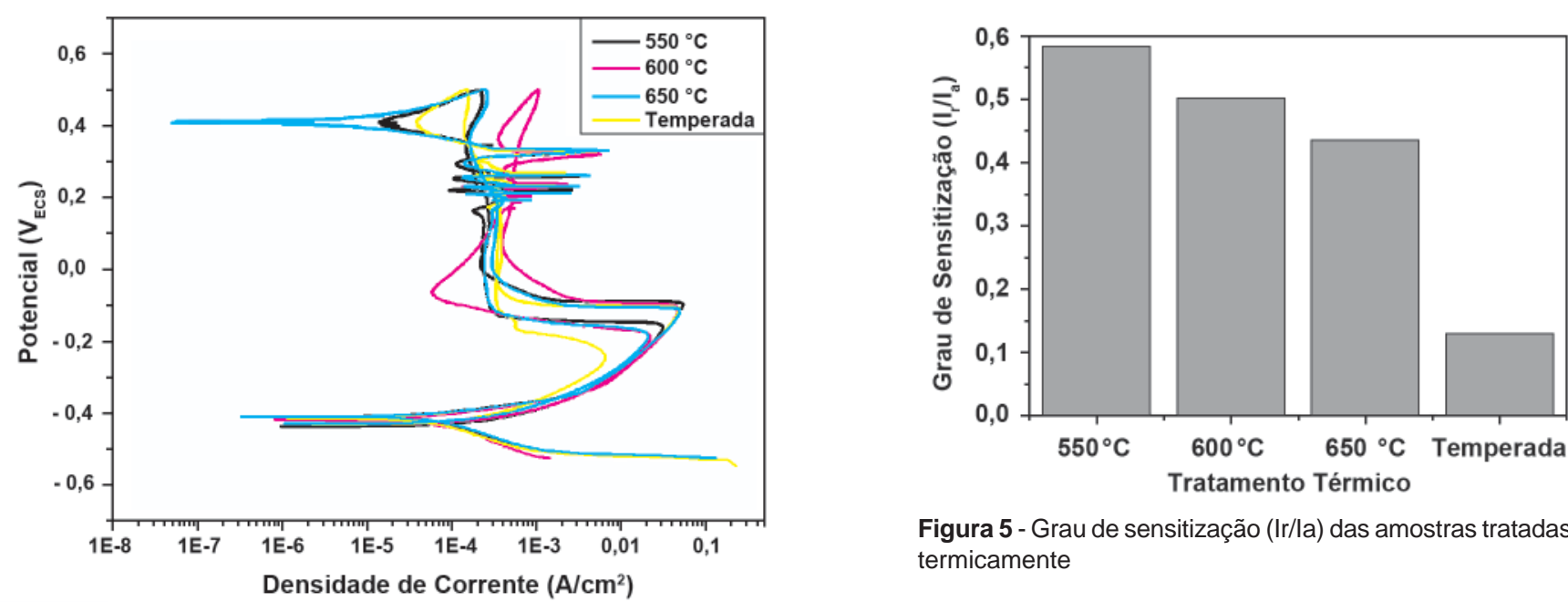

Figura 5 - Grau de sensitização (Ir/la) das amostras tratadas termicamente

Figura 4 - Grau de sensitização (I/I ) das amostras tratadas termicamente.

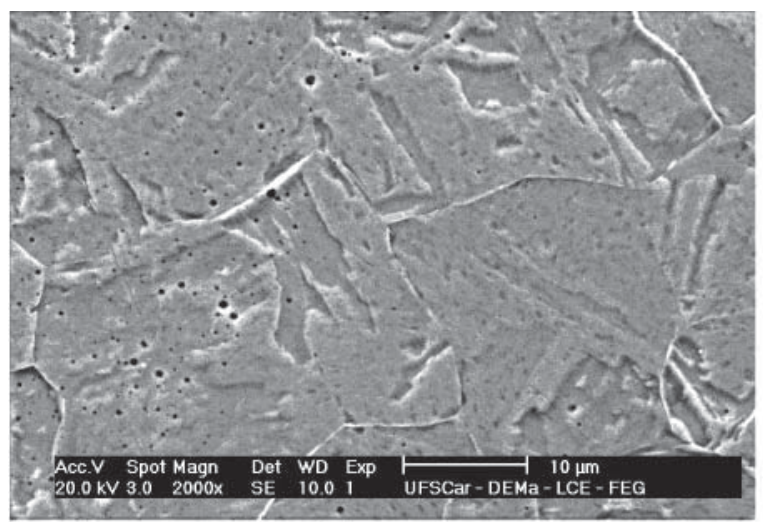

(a)

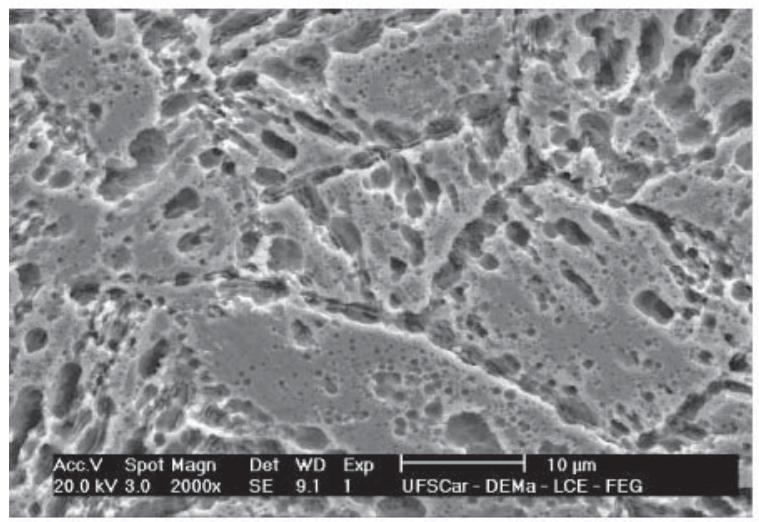

(c)

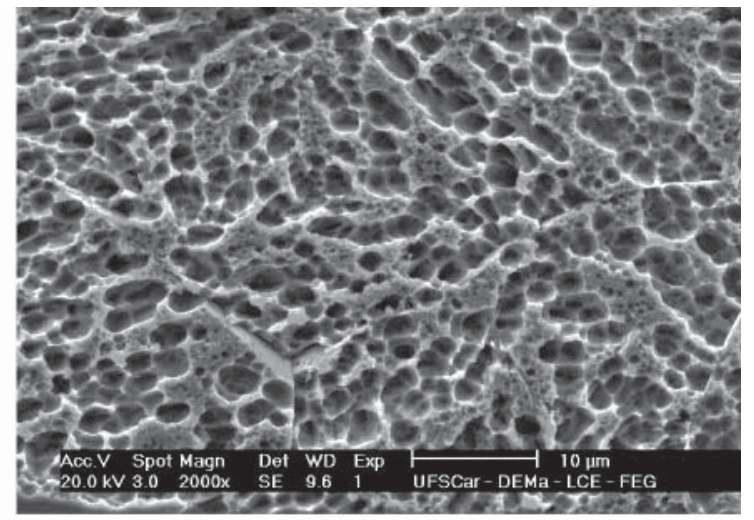

(b)

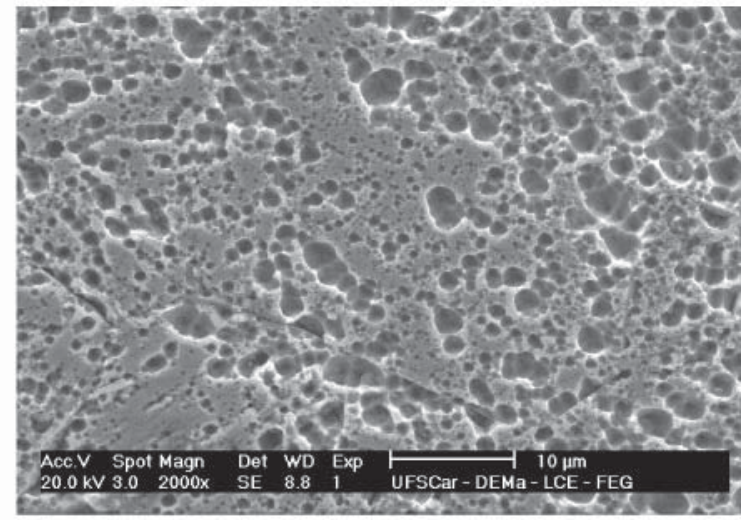

(d)

Figura 6 - MEV após o ensaio de DL-EPR da superfície das amostras (a) temperada, (b) revenida a $550^{\circ} \mathrm{C},(\mathbf{c})$ revenida a $600^{\circ} \mathrm{C}$ e (d) revenida a $650^{\circ} \mathrm{C}$.

finamente dispersa pela matriz martensítica, não é observada por microscopia ótica, e é estabilizada por processo de segregação até que não pode ser mais transformada, mesmo quando resfriada a baixíssimas temperaturas. Esse efeito produz um aumento da tenacidade desses aços (Toussaint \& Dufrane, 2002). O efeito dessa austenita, na resistência à corrosão, é polêmico e, ainda, não foi esclarecido (Kimura et al., 2001; Bilmes et al., 2006).
O potencial de corrosão, para todas as amostras, é próximo de - $420 \mathrm{mV}_{\mathrm{ECS}}$. Entretanto os valores de densidade de corrente critica e passiva são diferentes, mostrando que a facilidade de formação e a qualidade do filme passivo são 
influenciadas pelo tratamento térmico. Além disso, todas as amostras apresentaram um segundo pico anódico em torno de $100 \mathrm{mV}_{\mathrm{ECS}}$. Segundo a literatura, o segundo pico anódico pode ser provocado pela oxidação do hidrogênio atômico adsorvido no metal, presença de $\mathrm{Fe}^{2+}$ em solução ácida, tempo de imersão do eletrodo, enriquecimento de níquel na superfície do eletrodo e presença de regiões empobrecidas em cromo (sensitização). Alonso-Falleiros et al. (1999), após um curto período de imersão do eletrodo de trabalho, atribuíram o surgimento do segundo máximo anódico na curva de polarização de um aço inoxidável martensítico convencional em solução de $\mathrm{H}_{2} \mathrm{SO}_{4}$ à presença de regiões empobrecidas em cromo. No entanto, para o aço inoxidável supermartensítico, o surgimento do segundo pico anódico requer investigação adicional, uma vez que esses aços possuem um maior teor de níquel em sua composição e, no presente estudo, mesmo as amostras temperadas também apresentaram o surgimento do segundo pico anódico.

A diminuição da resistência à corrosão, após o tratamento térmico de revenido, é atribuída à precipitação de carbonetos ricos em cromo nos contornos de grão e entre as ripas de martensita. A formação desses carbonetos provoca o empobrecimento de cromo na matriz adjacente (Truman, 1976).

A amostra revenida a $550^{\circ} \mathrm{C}$ apresenta um ataque profundo, tanto nos contornos de grão, como entre as ripas de martensita, indicando um grande número de zonas empobrecidas em cromo. Nessa condição de revenido além da precipitação de carbonetos, deve-se, também, considerar as tensões residuais provenientes da têmpera que não foram totalmente aliviadas durante o revenimento.

$\mathrm{Na}$ amostra revenida a $600^{\circ} \mathrm{C}$, $\mathrm{o}$ ataque ocorre ao longo dos antigos contornos de grão da austenita prévia e entre as ripas de martensita. No entanto, o ataque é menor do que aquele produzido no material revenido a $550^{\circ} \mathrm{C}$, como observado na Figura 6 (c).
A amostra revenida a $650^{\circ} \mathrm{C}$ apresenta o menor ataque entre as amostras revenidas. Essa observação sugere que, no revenido, a temperaturas maiores, ocorre a recuperação das zonas empobrecidas em cromo, através da difusão de cromo da matriz para as regiões empobrecidas. Esse fato pode ser observado na Figura 6 (d), uma vez que não apresenta indícios de corrosão localizada em contorno de grão, como observado na Figura 6 (c).

\section{Conclusões}

1. O revenido a $650^{\circ} \mathrm{C}$ induz a formação de austenita.

2. O revenido promove precipitação de fases, provavelmente carbonetos ricos em cromo.

3. A presença de novas fases modifica significativamente, o comportamento anódico.

4. O revenido altera a resistência à corrosão, com o grau de sensitização diminuindo com o aumento de temperatura de $550^{\circ} \mathrm{C}$ para $650^{\circ} \mathrm{C}$ devido à recuperação das zonas empobrecidas de cromo.

\section{Agradecimentos}

Os autores agradecem ao CNPq e à CAPES pelo suporte financeiro imprescindível para realização desse trabalho.

\section{Referências bibliográficas}

ALONSO-FALLEIROS, N. et al. Intergranular corrosion in a martensitic stainless steel detected by electrochemical tests. Corrosion, v. 55, n. 8, p. 769-778, 1999.

AMERICAN SOCIETY FOR TESTING AND MATERIALS (ASTM). E 975-95: Standard practices for $\mathrm{x}$-ray determination of retained austenite in steel with near random crystallographic orientation - Designation E 975 - 95. In: Annual Book of ASTM Standards. Philadelphia: 1998.

BILMES, P.D. et al. Microstructure and pitting corrosion of 13CrNiMo weld metals. Corrosion Science, v.48, p.3261-3270, 2006.

CROWE, K.V., PICKERING, D.J. The physical metallurgy of $12 \%$ chromium steels. Journal of the Iron and Steel Institute, p.386-405, agosto, 1960.

DUFRANE, J. J. Metallurgical basis for the development of weldable martensitic stainless steels. In: SUPERMARTENSITIC STAINLESS STEELS 99, 1999, Bruxelas. In: Anais... Bruxelas, 1999. p. 19-24.

KIMURA, M. et al. Effect of retained austenite on corrosion performance for modified 13\% Cr steel pipe. Corrosion, v.57, n.5, p.433-439, 2001.

KONDO, K. et al. Alloy design of super 13Cr martensitic stainless steel (development of super 13Cr martensitic stainless steel for line pipe-1). In: SUPERMARTENSITIC STAINLESS STEELS 99, 1999, Bruxelas. In: Anais... Bruxelas, 1999. p. 11-18.

LIM, L.C. et al. Tempering of AISI 403 stainless steel. Materials Science and Engineering A, v.171, p.13-19, 1993.

MIAO, B. et al. Microstructure of tempered AISI 403 stainless steel. Materials Science and Engineering A, v.171, p.21-33, 1993.

SMITH, L., CELANT M. Martensitic stainless steels in context. In: SUPERMARTENSITIC 2002, 2002, Bruxelas. In: Anais... Bruxelas, 2002. p. 14-20.

TOUSSAINT, P., DUFRANE, J. Advances in the making and base material properties of supermartensitic stainless steels (SMSS). In: SUPERMARTENSITIC 2002, 2002, Bruxelas. In: Anais... Bruxelas, 2002. p. 23-27.

TRUMAN, J. E. Corrosion resistance of $13 \%$ chromium steels as influenced by tempering treatments. British Corrosion Journal, v. 11, n. 2, p. 92, 1976.

Artigo recebido em 06/08/2009 e aprovado em 18/01/2010. 